\begin{tabular}{lllll}
\hline Motrivivência & Ano XX, & No 31, P. & $192-206$ & Dez./2008 \\
\hline
\end{tabular}

\title{
Formação Continuada do Professor de Educação Física e a Construção de Práticas Pedagógicas Multiculturalmente Orientadas
}

Joe Gomes?

\section{Resumo Abstract}

O presente trabalho faz uma análise quantitativa e qualitativa sobre as dissertações e teses que abordam a articulação dos campos formação continuada dos professores de Educação Física e multiculturalismo na construção de práticas pedagógicas. Inicialmente faço uma investigação sobre a articulação dos campos, formação continuada dos professores de Educação Física

e multiculturalismo, procurando no banco de dissertações e teses, obtidos no site da ANPED, no período de 1999-2008, nos estudos sobre formação continuada e inicial de professores de Educação Física publicados em periódicos das áreas
The present work has objective you make quantitative and qualitative analysis on the texts and that approach the joint of the subjects continued formation of the professors of Physical Education and in the construction of practical pedagogical multiculturalism guided. Initially I make an inquiry on the joint of the fields, continued formation of the professors of Physical Education and multiculturalismo. You follow I investigate, in the bank of texts and, gotten in the site of the ANPED, the period of 1999-2008, the studies on continued and initial formation of periodic published professors of Physical Education in of the areas of Education and Physical Education, the practical works on

Mestrando em Educação pela Universidade Federal do Rio de Janeiro, Prof. de Educação Física da rede municipal do Rio de Janeiro, Especialista em Educação Física escolar pela Universidade Federal Fluminense. Contato joegomes1@ig.com.br 
de Educação e Educação Física, trabalhos sobre construção de práticas pedagógicas associadas às questões de discriminação étnica, de

raça, gênero e padrão e deficiência corporal, verificando lacunas para

futuras pesquisas. $\mathrm{O}$ intuito é a partir dessas lacunas analisar as possibilidades de elaboração de práticas pedagógicas que atentem às questões de discriminação cultural, apontando possíveis articulações entre a formação continuada e a construção de práticas pedagógicas à

luz da teoria multicultural crítica.

Palavras-chaves: Formação continuada de professores de Educação

Física; Práticas pedagógicas, Inter/ multiculturalismo crítico construction of pedagogical associates you the questions of ethnic discrimination, of race, sort, corporal standard and its oscillations how much you the growth and fall in to number of productions. Finally from these gaps I look will be you analyze the possibilities of practical studies will be elaboration of pedagogical that attempt against you the questions of cultural discrimination, pointing possible joints between practical the continued formation and the construction of pedagogical you the light of the critical multicultural theory.

Keys-word: Continued formation of professors of Physical Education; Practical pedagogical; Critical inter/ multiculturalism

\section{Introdução}

Estamos vivendo um contexto educacional marcado por inúmeros desafios pedagógicos, em função de processo de mudanças culturais oriundas de políticas públicas de inclusão escolar e o impacto da escolarização no processo de formação cultural dos alunos. Os desafios não mais pelo acesso se concentram em questões de elaboração de práticas pedagógicas à eliminação da discriminação e preconceito provenientes das diferenças culturais.

No que se refere à formação do professor de Educação Física

que atuam nas escolas públicas, tensões e conflitos são constantes, tornando-a um momento desafiador para que esses sujeitos sejam conduzidos à reflexão e construção de práticas pedagógicas. Um dos desafios é abranger as tensões e conflitos no processo de discriminação e preconceito entre os alunos durante as aulas.

Ao refletirmos sobre a sua realidade escolar o professor de Educação Física, analisando as conseqüências da discriminação pela diferença cultural entre os alunos, discursos e atitudes de rejeição aos colegas e atividades, descompromisso com a aprendizagem, disputas 
pela utilização dos recursos e ocupação dos espaços. Deparamos com necessidades de incluir os alunos e suas culturas na cultura da escola e da área, por vezes tencionamos eliminar atitudes discriminatórias e preconceituosas dos alunos por capacidades e habilidades técnicas, padrão corporal, origem étnica e gênero, mas as intenções de transformar a conduta dos alunos que atendam às vicissitudes da sociedade atual esbarram em uma realidade escolar onde estes nem sempre estão dispostos a colaborar, ou seja, cumprir ordens e realizar as tarefas sugeridas.

A formação continuada do professor de Educação Física emerge então como um campo rico de discussões. A função de orientar os professores na compreensão da discriminação e preconceito entre os alunos e a articulação entre o projeto de formação cultural com a construção de práticas pedagógicas, gera desafios aos pesquisadores, coordenadores e professores formadores, ao procurar soluções pedagógicas ao encontro do diálogo entre as culturas na escola, exigindo propostas de práticas pedagógicas que vão além da inclusão escolar.

A formação continuada como campo de reflexão de propostas de práticas pedagógicas da Educação Física, construída sob o paradigma das teorias de inclusão cultural, exigem reflexões sobre a função dos professores no processo de discriminação e preconceito entre os alunos.

Que propostas de práticas pedagógicas multiculturalmente orientadas estão sendo construída nas escolas e em particular nas aulas de Educação Física? Em que medida essas propostas atentam minimizar a discriminação e preconceito entre os alunos do $6^{\circ}$ ao $9^{\circ}$ ano do ensino fundamental?

Este trabalho visa analisar a articulação dos estudos de formação continuada de professores e em particular dos professores de Educação Física com a teoria multicultural crítica, na construção de práticas pedagógicas às questões de discriminação e preconceito cultural de: gênero, etnia, orientação sexual, padrão corporal, de competência e habilidade técnica, identificando desafios pedagógicos em função das relações de poder, conflitos e tensões entre os alunos.

Inicialmente analiso possíveis articulações entre o campo de formação continuada de professores articulados e do multiculturalismo, apontando os desafios para articulação entre os campos.

A seguir analiso no campo de formação continuada em Educação Física, dissertações, 
teses e artigos publicados no site da Associação Nacional de Pósgraduação em Educação (ANPED) e periódicos da área de Educação e Educação Física, no período de 1999-2008, as propostas de práticas pedagógicas articuladas as teorias do multiculturalismo e às categorias multiculturais como raça, etnia, gênero, orientação sexual, corpo, competências e habilidades.

Finalmente analiso o processo de construção de práticas pedagógicas multiculturalmente orientadas, discutindo a discriminação e o preconceito entre os alunos e apresentando propostas à luz da teoria inter/multicultural crítica que supere os desafios pedagógicos de compreender a discriminação e o preconceito entre os alunos para além da inclusão cultural.

Argumento a posição de se relacionar o campo da formação continuada do professor de Educação Física com a perspectiva inter/ multicultural para construção de práticas pedagógicas. Valorizando as diferenças culturais, pesquisando ações que vão além do conhecimento histórico e celebração das culturas, construindo relações interculturais entre os alunos, questionando o preconceito e a discriminação como um processo "natural" de inclusão e de "tolerância" entre os sujeitos.

\section{A formação continuada e os desafios à articulação com uma perspectiva inter/multi- cultural}

A formação continuada dos professores embora seja um tema de extrema importância para educação nacional, não vem como os demais temas do campo educacional nos últimos dez anos, crescendo no Brasil. As mudanças no contexto escolar provenientes das vicissitudes e desdobramento das leis, a entrada em grande escala de alunos das classes populares e suas culturas nas escolas públicas, embora provoquem inúmeras e conflituosas inquietações ainda não sensibilizou um contingente significativo de pesquisadores.

André et all (1999) analisando o tema a partir de dissertações e teses defendidas no período de 1990-1996 mostrou que embora essas produções quase dobrassem a formação dos professores não tem acompanhado o crescimento do campo educacional, mantendo-se em posição estável sobre o volume total das produções.

A formação continuada, no contexto da produção científica, apresentou neste período um volume de $14,8 \%$ sobre o total ficando bem aquém da preocupação com a formação inicial $(76 \%)$. Os estudos 
sobre este tema embora em número reduzido mostram-se bastante variados em relação aos conteúdos investigados, níveis de ensino, contextos escolares e utilização de meios de comunicação e materiais. As autoras tecem algumas observações quanto às análises pontuais, disciplinas, programas, propostas de formação, avaliações do currículo e funcionamento dos cursos. Apresentam questionamentos sobre lacunas dessas pesquisas em relação aos processos e práticas de uma formação dos professores mais efetiva ao contexto escolar atual (André et. All, 1999).

Moreira (2001) investigando a produção no campo educacional, em 46 textos de pesquisadores brasileiros em artigos publicados em periódicos nacionais como Caderno de Pesquisa, Revista Brasileira de Educação, Educação e Realidade, Educação e Sociedade e Educação e Revista, relacionando currículo, escola e multiculturalismo ou categorias como classe social, etnia, gênero, orientação sexual e cultura em instituições escolares e arranjos curriculares, identifica em menos de $4 \%$ das produções (4) a relação entre multiculturalismo e formação docente.

Os textos defendem a formação de um professor reflexivo e multiculturalmente competente, sugere a inclusão de disciplinas à educação multicultural, adendos ao currículo de formação, interação dos futuros docentes com as realidades escolares e preparação dos professores para os desafios oriundos da pluralidade social e das escolas. O referido autor critica o quantitativo de estudos que evidenciam uma orientação multicultural, constituindo-se em uma lacuna do campo a ser preenchida (Moreira, 2001, p. 67- 71).

Souza (2005) em estudo que relaciona o pluralismo cultural, multiculturalismo e formação de professores propõem debater alguns aspectos que visam espaços para as discussões étnicas nos cursos e as possibilidades de um currículo multicultural. Orientando o professor para que além de conhecer a questão racial comprometer-se politicamente com ela, por meio de um projeto educacional emancipatório que defina a origem do conflito, visto que, segundo a autora, ele surge num espaço intercultural.

A teoria inter/multicultural crítica no campo da formação continuada visa discutir os conflitos e tensões no processo de discriminação e preconceito cultural dos sujeitos encontrados nos diferentes universos escolares. Procura nos valores culturais dos excluídos por etnia, gênero e orientação sexual, em função da dominação e homogeneização cultural, práticas 
emancipatórias de luta contra as desigualdades escolares e sociais, que se sucedeu historicamente no Brasil. Suas funções não se restringem em apenas identificar os atos discriminatórios, preconceitos e formas amenas de apaziguamento, mas encontrar meios de compreender a resistência ao etnocentrismo cultural daqueles vistos como "diferentes", "rebeldes", além de criticar as teorias de naturalização das culturas, ainda presentes no campo de formação, e refletir sobre a articulação entre a formação e a prática pedagógica a partir das ações dos sujeitos ( Moreira, 2003; Canen 2008).

Canen (2008) considera que o campo da formação de professores como "espaço discursivo e privilegiado para construção de identidades docentes multiculturalmente orientadas..." (CANEN, 2008, p.19), ressente de um maior diálogo com os autores do multiculturalismo e de trabalhos que analisem o currículo em ação na formação dos professores nessa perspectiva. Sugere que esta articulação se faça sob duas perspectivas; uma propondo a investigação sobre os próprios processos que envolvem a pesquisa na formação de professores, compreendida como relações de poder desiguais e informada por universos de diversas culturas, e uma outra perspectiva que argumente a rele- vância da articulação da pesquisa em formação docente com a teoria multicultural.

A perspectiva inter/multicultural crítica de formação dos professores construída à luz dos estudos do Interculturalismo (Candau, 2005; Candau, 2007; Candau, 2008; Fleuri, 2008, Marin, 2008) e do Multiculturalismo crítico (Mac Laren, 2000, Canen, 2002; Canen, 2003; Canen, 2008; Canen, 2009), entende a formação continuada como espaço de construção de práticas pedagógicas pelos professores que atuam nas escolas, visando discutir questões que geram os preconceitos e discriminações étnicas, de gênero e sexo, e procurando romper "uma relativa independência com que ambos os campos têm sido pensados" (Canen, 2008, p.18).

A articulação entre os campos de formação continuada e inter/multiculturalismo, por meio de ações dos pesquisadores e dos professores, ainda apresenta lacunas na construção de práticas pedagógicas, precisa serem preenchida com o trabalho mútuo desses sujeitos (Canen, 2008). Essa articulação assegura discussões em torno do processo de discriminação e preconceito dentro do contexto escolar.

Sendo assim alguns questionamentos a norteiam; $\mathrm{O}$ que fomenta as pesquisas de formação 
continuada multicultural crítica? Em que proporção às práticas pedagógicas tem um potencial multicultural para discutir a discriminação e o preconceito com a cultura dos alunos? Quais os desafios postos para construção dessas práticas em escolas públicas?

Conforme Canen (2008) a perspectiva multicultural, também entendida como pós-colonial ou intercultural, "busca não somente a valorização da pluralidade cultural como questionamento e problematização do processo de construção da identidade, da alteridade e das diferenças" (Canen, 2008, p.20). Nesse sentido os objetivos, os princípios, as categorias hibridização e crítica cultural, e as estratégias para orientam os professores à compreensão das diferenças entre os alunos, fomentam as pesquisas que articulam formação continuada, estudos do inter/multiculturalismo crítico e construção de práticas pedagógicas.

Nesse sentido os principais desafios dos estudos de formação continuada dos professores de educação Física em uma perspectiva inter/multicultural crítica é investigar práticas que discutam às diferenças culturais relacionas às questões de discriminação étnica, racial, de gênero, orientação sexual, padrão e deficiência corporall.

\section{A formação continuada do professor de Educação Física: investigando o processo de construção de práticas}

Observamos nas realidades escolares, e especificamente no contexto atual da Educação Física escolar: relativismo de interesses; rejeição às atividades de movimento, isolamentos de indivíduos e grupos, formação dos "guetos" de difícil integração com as culturas corporais e enfrentamentos ao professor por exigência de determinadas de maior interesse dos alunos. Constituem-se como novos desafios à formação do professor, compreender a diferença cultural como encontro das culturas e das múltiplas linguagens corporais dos alunos.

No que se referem à formação continuada dos professores de Educação Física conflitos e tensões ideológicas marcam o campo. A função de atualizar os professores para atuarem na escola pública, condição central para que possam lidar com as vicissitudes das realidades escolares, em um contexto onde diferentes culturas se entrecruzam, requer comprometimento com a equidade social e educacional, compreender as inúmeras culturas trazidas pelos alunos e criticar as propostas de discriminação e preconceito.

Nesse sentido a perspectiva intercultural ou multicultural 
crítica de formação continuada dos professores tem apresentado um reduzido número de propostas à construção de práticas pedagógicas para valorização das culturas trazidas pelos alunos para o contexto escolar e de, análises sobre a diferença.

Entendendo a diferença como "distribuição desigual entre as pessoas na organização social, decorrente de aspectos que 'centralmente' as distinguem, do que à ideia de grupos e indivíduos distintos partilhando aspectos comuns a uma única raça - a humana" (Moreira, 2001, p.66). Os objetivos da formação continuada orientada multiculturalmente podem centralizar-se também na função do professor de Educação Física em discutir a discriminação e o preconceito entre os alunos nas aulas.

No que diz respeito à valorização das diferentes culturas dos alunos e eliminação da discrimina- ção e o preconceito exige-se, portanto, do professor de Educação Física, compromisso político e desafio pedagógico no processo de construção de práticas, comprometimento com a inclusão dos sujeitos discriminados e enfrentamento as atitudes de exclusão por questões de gênero, etnia, raça e orientação sexual.

Constatamos dialogando com as análises de Oliveira e Silva, Janoario e Canen, (2007), que a articulação entre os campos de formação continuada do professor de Educação Física e Multiculturalismo ainda não está plenamente contemplada. Verificamos ao analisar quantitativamente e qualitativamente o campo de formação continuada dos professores de Educação Física, que nas revistas qualis B2, avaliada pela CAPES, Revista Brasileira de Educação (RBE), Cadernos CEDES, Caderno de Pesquisa e Educação e Realidade, que esta articulação, conforme tabela abaixo, é nula.

\begin{tabular}{|l|c|c|c|c|c|c|c|c|c|c|}
\hline ano & 1999 & 2000 & 2001 & 2002 & 2003 & 2004 & 2005 & 2006 & 2007 & 2008 \\
\hline RBE & 0 & 0 & 0 & 0 & 0 & 0 & 0 & 0 & 0 & 0 \\
\hline CEDES & 0 & 0 & 0 & 0 & 0 & 0 & 0 & 0 & 0 & 0 \\
\hline $\begin{array}{l}\text { Edu. e } \\
\text { Realidade }\end{array}$ & 0 & 0 & 0 & 0 & 0 & 0 & 0 & 0 & 0 & 0 \\
\hline
\end{tabular}

Buscando informações em periódicos da área de Educação Física, investigamos nas revistas, também avaliadas pela CAPES como qualis $B$, Pensar a prática (UFG),
Motrivivência, Movimento (UFRGS) e Revista de Educação Física, Esportes, Lazer e Dança (REFELD) não foi encontrada a articulação entre os termos multiculturalismo e forma- 
ção continuada dos professores de Educação Física.

Ao realizarmos consultas no site da ANPED (Associação Nacional de Pós-graduação e Pesquisa em Educação), referência teórica na área educacional pelo volume de informações sobre as pesquisas educacionais mais recentes no país, no banco de teses da CAPES, disponibilizado para informações das produções sobre dissertações e teses, pudemos constatar, no período de 1999-2008, que os reduzidos dados quantitativos e qualitativos das pesquisas ratificam a existência de inúmeras lacunas nos estudos na formação continuada dos professores de Educação Física à compreensão das diferenças culturais étnico-raciais, de gênero, padrão e deficiência corporal e orientação sexual, dificultando a fundamentação do professor de Educação Física para os contínuos atos discriminatórios que ocorrem nas aulas.

\section{Análise das dissertações e teses}

Stefane (2003), fazendo uma análise de autores brasileiros e estrangeiros do campo de formação continuada da Educação Física, identificou uma pequena diferenciação entre os cursos de formação inicial e continuada centralizados em modalidades esportivas, distanciamento dos professores das produções científicas, das políticas públicas, de eventos científicos e das novas abordagens da Educação Física escolar. A autora constata que a formação do professor de Educação Física não tem contribuído para provocar mudanças nas suas atitudes ante a participação dos alunos, ampliação do universo da cultura corporal da Educação Física limitando-se aos esportes de quadra e a rigidez das suas regras, práticas de atividades simultâneas para ambos os sexos, dificuldades de compreensão da fundamentação teórica (Stefane, 2003, p. 14-15).

Ao analisar as percepções de 62 professores da área que atuam com alunos do $3^{\circ}$ e $4^{\circ}$ ciclo do ensino fundamental ( $6^{\circ}$ ao $9^{\circ}$ ano) e médio, a partir de situações hipotéticas, pode concluir a necessidade dos professores em serem orientados sobre assuntos que envolvem questões étnicas, religiosas e raciais visto que suas atitudes e práticas pedagógicas partem de valores pessoais. A autora sugere na formação de professores de Educação Física compromisso político, mudança na organização, currículo e estruturas que possibilitem o sucesso de todos os alunos. Oliveira e Silva (2008), analisando as possibilidades de formação do professor de Educação 
Física multicultural, investigando as produções do campo e a partir da análise crítica dos documentos Multieducação (SME/RJ, 1996) e DCN (MEC, 2004) e entrevista com os sujeitos dos cursos de formação continuada, percebeu inúmeras lacunas no processo de formação inicial e continuada, e apesar da intenção pelas discussões sobre as questões de etnia, gênero, raça e orientação sexual não identificou um viés multicultural crítico.

Identificamos, portanto, que apesar de se constituir como uns dos mais importantes temas de discussão para formação continuada do professor de Educação Física, face os inúmeros conflitos vividos nas escolas públicas, as questões de diferença cultural que corroboram ações de discriminação e preconceito étnico, de gênero e sexo, não estão plenamente contempladas pelo reduzido número de trabalhos. Verificamos com um olhar "otimista crítica" (Charlot,2000) a significativa intenção dos reduzidos estudos em apresentar os discursos dos sujeitos do processo de formação continuada, trazendo para o campo as vozes silenciadas.

Essas análises revelam que a formação continuada do professor de Educação Física, não está totalmente articulada com as perspectivas multiculturais crítica (pós-colonial, intercultural e multicultural), o que dificulta a orientação à construção de práticas pedagógicas que discutam a discriminação e os preconceitos étnicos, raciais, religiosos, sociais, de gênero e orientação sexual, pelo viés do conflito e das relações de poder. Os estudos não se revelaram, ainda, suficientes à mudança do quadro das realidades escolares sobre as questões que possam nortear a construção de práticas que atentam à diferença cultural.

\section{As possibilidades de articu- lação entre os campos de formação continuada em Educação Física e Multicultu- ralismo: desafios à construção de práticas pedagógicas mul- ticulturalmente orientadas}

Apesar da reconhecida evolução do campo da Educação Física a partir da década de 1990 (Ludorf, 2001), a articulação do campo de formação continuada da área com o Multiculturalismo, que viabilizaria inúmeras ações do professor que atua na escola pública em relação às práticas discriminatórias, é ignorada.

No processo de articulação do discurso com a prática e na ruptura com as teorias iluministas modernas sobre a discriminação e o preconceito, vislumbram-se as possibilidades de articulação entre o 
campo de formação continuada dos professores de Educação Física com a perspectiva multicultural crítica na construção de práticas pedagógicas à transformação da realidade escolar e das aulas de Educação Física como espaço-tempo de valorização e construção das diferenças.

Os estudos de formação continuada do professor de Educação Física construídos a partir de uma perspectiva multicultural crítica podem apontar para construção de práticas que valorizem as diferenças culturais?

A fragmentação dos sujeitos, conforme Hall (2007), presentes em tempos de incerteza e provisoriedade, inviabilizaram o projeto de educação escolar moderna baseada no iluminismo. A ruptura com esse modelo de educação implica na ruptura com as teorias de racionalidade técnica que são predominantes em muitos currículos de formação do professor de Educação Física.

Nesse sentido é tarefa do campo de formação continuada em Educação Física pesquisar práticas orientações multiculturalmente, que atentam à discriminação e o preconceito e valorização das diferenças culturais.

\section{Conclusão}

A partir destas afirmações seria importante considerarmos algumas questões:
Que objetivos à formação continuada dos professores de Educação Física em uma perspectiva multicultural precisam ser delineados para fundamentar a valorização das diferenças culturais entre os alunos? Que articulações seriam possíveis entre os estudos do campo de formação continuada da Educação Física com as perspectivas multiculturais críticas? Como categorias e temas como raça, etnia, gênero, orientação sexual, padrão e deficiência corporal se tornam centrais na construção de práticas pedagógicas multiculturalmente orientadas? Que sugestões de estratégias surgiriam à ação-reflexão dos professores em relação à discriminação e do preconceito entre os alunos nas aulas de Educação Física?

Um encaminhamento inicial para encontrar as respostas a estes questionamentos é oriundo dos estudos que analisam criticamente as teorias e práticas de formação continuada dos professores de Educação Física que se apóiam nas intenções de padronização e homogeneização cultural dos alunos e no currículo monocultural. Nesse sentido entendemos como condição básica a superação do modelo etnocêntrico, buscando refletir sobre meios de transformar a realidade social e em particular das escolas públicas, apontando aos professores caminhos no processo 
de construção de práticas pedagógicas multiculturalmente orientadas.

Consideramos como práticas multiculturais ou com potencial multicultural aquelas cujos discursos e ações se inserem no processo de transformação da realidade social e em particular do contexto escolar onde é realizada. Procurando meios de evidenciar os conflitos e lutas a respeito da discriminação e preconceito cultural, social, econômico, político às questões étnicas, de raça, gênero e orientação sexual, padronização do comportamento(Canen, Abrache e Franco, 2004).

O desafio à construção de práticas pedagógicas multiculturais na formação continuada tem sido compartilhado por diferentes autores/as (Canen e Oliveira, 2002; Canen, 2009; Candau, 2007; Candau, 2008, Moreira, 2008). Canen e Oliveira (2002) criticam o "modismo" como vem sendo tratado o tema. As autoras relacionam as identidades étnicas, raciais, de gênero, sistematicamente silenciadas em currículos monoculturais e homogeneizadores às consequências à formação de professores e a visão reducionista de valorização da diversidade cultural com foco na essencialismo e no folclorismo. Nessa perspectiva as orientações da formação continuada em Educação Física propõem-se acrescentar novos conteúdos e práticas pedagógicas comemorativas, datas de celebração aos atos de heroísmo ou de "lembranças" da existência de algumas etnias, compreensão e valorização das relações humanas pela tolerância entre os sujeitos, como por exemplo, a inclusão de esportes radicais no currículo escolar, o dia da "atividade física na escola", "pesquisa sobre os jogos indígenas", "pesquisa sobre o folclore", "dia do amigo na escola".

Essa perspectiva ao não romper com o preconceito, não revela as dicotomias, exclusões, tensões e conflitos contra e entre aqueles entendidos como "diferentes" e "normais", entre o "eu" e o "outro", investigando tão somente as suas origens ou celebrando eventualmente a sua existência, dificultam a superação das adversidades, dessa forma inviabiliza que no futuro, conforme nos ensina Boaventura Souza Santos, haja respeito e valorização entre as culturas e sujeitos, e se perceba a diferença entre os diferentes.

Que desafios à superação da diferença cultural entre os alunos, por meio de discursos e práticas, são enfrentados pelos professores de Educação Física, para eliminar o preconceito e discriminação dos alunos contra raças, etnias, gênero e orientação sexual diversas?

Celebrar e reconhecer as histórias dos grupos étnicos e seus heróis, propor a tolerância pela 
simples inclusão do outro ou criar "adendos" ao currículo no intuito de promover a equidade racial e social, atentam às intenções políticopedagógicas de contraposição à dominação cultural?

Ao não discutirem as questões que permeiam os conflitos, tensões e relações de poder entre os sujeitos na sociedade (Canen, 2005), ao focar especificamente as relações humanas sem atentar às questões de eliminação e submissão do outro presente no sistema social e escolar, dificilmente teremos na formação do professor de Educação Física da escola pública, o engajamento político com posturas críticas pela transformação dos modelos educacional e social vigente, e principalmente pelas lutas contra a discriminação velada ou frontal em relação aos mais humildes e criticados pelo "fracasso", pela "falta de competência" ou "vontade pessoal" (Boyle e Gillete, 1998; Silva, 2000 apud Canen e Oliveira, 2002).

\section{Referências}

ASSIS \& Canen, A. Identidade negra e espaço educacional: vozes, histórias e contribuições do multiculturalismo, caderno de pesquisa, v.34, n. 123, p. 709, set.2004.
BREZENINSKI I. \& Garrido, E. Análise dos trabalhos do GT Formação de professores: o que revelam as pesquisas do período 1992-199, Rev. Bras. de Ed. set/ dez. 2001, nº18.

CANDAU, Vera Maria, Sociedade multicultural: tensões e desafios, In; Candau, Vera Maria (org.), Cultura(s) e educação: entre o crítico e o pós-crítico, RJ-RJ, DP\&A, 2005.

\& Leite, Miriam S. A didática na perspectiva multi/intercultural em ação: construindo uma proposta, Caderno de Pesquisa v. 32 , n. 132 , p.731-758, set/ dez, 2007.

Multiculturalismo e educação: desafios para prática pedagógica; In Candau, Vera M. \& Moreira, Antônio Flávio, (orgs.), Multiculturalismo: diferenças culturais e práticas pedagógicas, Petrópolis, RJ, Vozes, p.13-37, 2008.

CANEN, Ana \& Oliveira, Ângela M. A. de, Multiculturalismo e currículo em ação: um estudo de caso, rev. Bras. de Edu. set/ dez. 2002.

, Construção e reconstrução multicultural de identidades docentes: pensando na formação continuada de coordenadores pedagógicos, rev. Bras. Est. Pedag. Brasília, v. 87. n. 217, p. 339-348, set./dez. 2006. 
(orgs.), Educação Multicultural: teoria e prática para professores e gestores em educação, RJ, ed. Ciência Moderna Itda. 2009.

O multiculturalismo e seus dilemas: implicações na educação, Comunicação e política, v.25, n. ${ }^{\circ} 2$, p. 91-107, 2007.

, O multiculturalismo e o papel da pesquisa na formação docente: uma experiência de currículo em ação, currículo sem fronteiras v.8, n.1, pp.17-30, jan./jun. 2008.

FLEURI, Reinaldo M. Intercultural e educação, Rev. Brs. Edu. No23, p. 7-18, 2003.

GABRIEL, Carmen T. A identidade (nacional) na berlinda: uma forma possível de entrar no debate em torno da educação intercultural, In; Candau, Vera Maria (org.), Cultura(s) e educação: entre o crítico e o pós-crítico, RJ-RJ, DP\&A, 2005.

GIROUX, O pós-modernismo e o discurso da critica educacional; In; Teoria educacional crítica em tempos pós-modernos, Porto Alegre-RS, Artes Médicas, 1993.

XAVIER, Gisele P. M. A formação de professores para uma sociedade multicultural.

MOREIRA, Antônio F. B. A crise da teoria curricular crítica, In: Costa, Marisa V. O currículo nos limiares do contemporâneo, RJ: ed. DPA, p.11-26, 1998.

A recente produção científica sobre currículo e multiculturalismo no Brasil (1995-2000): avanços, desafios e tensões, Revista Brasileira de Educação, texto apresentado na 24a Reunião Anual ANPED, CAXUMBU-MG, 2001.

\& Câmara, Michele J. Reflexões sobre currículo e identidade: implicações para a prática pedagógica; In Candau, Vera M. \& Moreira, Antônio Flávio (orgs.) Multiculturalismo: diferenças culturais e práticas pedagógicas, Petrópolis, RJ, Vozes, p.13-37, 2008.

OLIVEIRA, Victor de \& Miranda, Ozerina C. Multiculturalismo crítico, relações raciais e política curricular: a questão do hibridismo na Escola Sarã, Rev. bras.edu. 67-81, 2004.

OLIVEIRA e SILVA, R. de Cássia, A formação multicultural do professor de Educação Física: entre o real e o possível, dissertação de mestrado, RJ; UFRJ, 2008.

ORTIZ, Renato, Anotações sobre o universal e a diversidade, ver. Bras. Educ. v.12 n.34 Rio de janeiro jan./abr.2007.

SANTOS, Boaventura S. Renovar a teoria crítica e reinventar a emancipação social, SP-SP, Boitempo editorial, 2007. 
SOUZA, Maria Elena V. Pluralismo cultural e multiculturalismo na formação professores: espaços para discussão étnicas de alteridade, ver. HISTEDBR Online, campinas, n. 19, p. 89-100, set.2005.

STEFANNE, Cláudia A. Professores de Educação Física: diversidade e práticas pedagógicas, tese de doutorado, São Carlos-SP: UFSCar, 2003.

Recebido: 11/fevereiro/2010. Aprovado: 21/abril/2010. 